\title{
Optimization and Modeling of Radial Pitch Diameter Difference in Tapping of AISI H13
}

\author{
Jie Ren, ${ }^{1}$ Tingting Li, ${ }^{2}$ Zhi Chen, ${ }^{1}$ Yu Meng, ${ }^{1}$ Rui Zhang, ${ }^{1}$ and Xianguo Yan ${ }^{1}{ }^{1}$ \\ ${ }^{1}$ School of Mechanical Engineering, Taiyuan University of Science and Technology, Taiyuan 030024, China \\ ${ }^{2}$ School of Pharmacy, Shanxi Medical University, Taiyuan 030001, China \\ Correspondence should be addressed to Xianguo Yan; botao12330@outlook.com
}

Received 7 November 2021; Accepted 21 January 2022; Published 8 February 2022

Academic Editor: Antonio Boccaccio

Copyright $\odot 2022$ Jie Ren et al. This is an open access article distributed under the Creative Commons Attribution License, which permits unrestricted use, distribution, and reproduction in any medium, provided the original work is properly cited.

\begin{abstract}
The radial pitch diameter difference has a great influence on the quality of the internal thread. However, it is difficult to accurately control the radial pitch diameter difference of the thread in the tapping. Therefore, the influence of various factors on radial pitch diameter difference for tapping AISI H13 steel was studied in this paper. Parameters with optimum radial pitch diameter difference were determined by the Taguchi method, and the tapping experiment was carried out according to Taguchi L18 orthogonal array. Based on the signal-to-noise ratio and variance analysis, the experimental results were evaluated to determine the combination of factors to obtain the smallest radial pitch diameter difference and the influence level of each factor on radial pitch diameter difference, and the prediction equation of radial pitch diameter difference was established through the regression analysis. The results show that the combination of factors to obtain the smallest radial pitch diameter difference is a hone radius of $10 \mu \mathrm{m}$, a spindle speed of $100 \mathrm{rev} / \mathrm{min}$, and a chamfer length of 2 pitches; the order of importance of the influencing factors on radial pitch diameter difference is spindle speed, followed by hone radius and chamfer length, and their percentage contribution rates are $61.54 \%, 24.53 \%$, and $6.16 \%$, respectively; the determination coefficient $R^{2}$ of the prediction equations is 0.925 ; the confirmation experiment conducted with $95 \%$ confidence level shows that Taguchi method and prediction equation successfully optimize and predict radial pitch diameter difference.
\end{abstract}

\section{Introduction}

Due to the advantages of simple structure, reliable connection, and convenient assembly and disassembly, threaded connections are widely used in energy, aerospace, high-speed rail, automobile manufacturing, and other fields [1-3]. Inferior threads not only reduce the performance of the product but also even bring huge safety hazards $[4,5]$. Therefore, it is of great significance to improve thread manufacturing quality and strengthen thread quality control [6].

As an important part of a threaded connection, internal thread exists in almost all mechanical components [7]. Tapping is the only method to manufacture small-diameter internal threads [8]. It is usually performed in the final stage of the manufacturing process. Any machining failure or reduction in precision cannot achieve the perfect assembly of components without gaps and even lead to huge economic losses $[9,10]$. In actual production, it is difficult to guarantee the manufacturing quality of internal threads due to the harsh processing conditions of tapping. In order to improve the thread quality of tapping processing, some scholars have conducted related research. Hsu et al. [11] analyzed the influence of the helix angle of the tap on the quality of thread manufacturing and found that a tap with a helix angle of $10-15^{\circ}$ can produce a relatively complete thread shape and better surface quality. Fernández Landeta et al. [12] compared the manufacturing accuracy of forming taps with different geometric parameters and found that the crosssectional shape and chamfer length have an effect on the accuracy of the thread. The focus of these studies is the thread surface quality, but in many cases, the thread performance cannot be effectively evaluated by the surface quality alone. The radial pitch diameter difference (RPDD) is regarded as an important parameter for evaluating thread 
quality. RPDD is a geometric error, which refers to the maximum difference between the radial pitch diameters within a lead (pitch for single thread) length, as shown in Figure 1. The RPDD $\left(\Delta \mathrm{D}_{2 \mathrm{r}}\right)$ of the thread can be determined by the difference between the maximum pitch diameter and the minimum pitch diameter in each radial direction of the actual thread.

$$
\Delta D_{2 r}=D_{2 r \max }-D_{2 r \min }
$$

In fact, due to the existence of RPDD, the contact area between the internal and external threads will change sharply, resulting in uneven load distribution on the thread surface, thereby accelerating wear and shortening the service life, and severely causing "looseness" or even "slip buckle." In the past, conservative process parameters were usually selected to ensure the thread quality. But today's fierce competitive environment requires producers to be enterprising [13]. Therefore, the parameters of tapping must be optimized to reduce manufacturing costs and improve the performance of mechanical products.

Taguchi method is a statistical method used to optimize designs for cost, performance, and quality. It can efficiently deal with multifactor problems with a small number of experiments, so it has been widely used in the field of engineering analysis. Vankanti and Ganta [14] studied the influence of process parameters such as cutting speed, feed rate, point angle, and chisel edge width in the drilling of glass fiber reinforced polymer composite materials on hole quality. The results show that the cutting speed is the most important factor affecting the roundness of the hole, followed by the feed speed, the chisel edge width, and the point angle. Ahmed and Arora [15] studied the influence of hone radius, cutting depth, and feed rate on surface roughness based on the Taguchi method and variance analysis and confirmed that hone radius is the biggest factor affecting surface roughness. Bhattacharyya et al. [16] studied the effect of micromilling parameters on average surface roughness of high purity aluminium and copper and determined the optimum milling conditions through the Taguchi method. The results show that the optimal surface roughness was obtained for aluminium and copper with spindle speed, feed, and depth of cut of $7000 \mathrm{rev} / \mathrm{min}, 30 \mathrm{~mm} / \mathrm{min}, 10 \mu \mathrm{m}$, and $4000 \mathrm{rev} / \mathrm{min}$, $20 \mathrm{~mm} / \mathrm{min}$, and $10 \mu \mathrm{m}$, respectively. Finally, quadratic regression equations relating roughness to speed, feed, and depth of cut are proposed with the correlation coefficients $\left(R^{2}\right)$ more than 0.985 . The purpose of this paper is to determine the optimal RPDD with a specific combination of parameters in tapping AISI H13 steel based on the Taguchi method. The signal-to-noise ratio $(\mathrm{S} / \mathrm{N})$ is used to determine the optimum combination of parameters. Through the analysis of variance (ANOVA), the influence level of each parameter on RPDD is determined. The prediction equation of RPDD is established by regression analysis (RA).

\section{Materials and Methods}

2.1. Material and Measurement. The machine tool and taps for tapping are shown in Figures 2(a) and 2(b). High-speed steel (AISI M2) straight flute tap obtained from Harbin
Shenxin Thread Tool Co., Ltd. is installed on a VMC850 vertical machining center with a power of $11 \mathrm{KW}$ through a BT40 floating tool holder during tapping. The geometric parameters of the tap are listed in Table 1. A plate of AISI $\mathrm{H} 13$ material in the form of $200 \mathrm{~mm} \times 200 \mathrm{~mm} \times 15 \mathrm{~mm}$ is used as the tapping sample, and the diameter of the predrilled hole for tapping was $6.8 \mathrm{~mm}$ (Figure 2(c)). The specific components of AISI H13 used in the experiment are listed in Table 2. After the tapping test, the RPDD of the threaded hole was measured by the GJ-5S Johnson Gage internal thread measuring instrument of Edmunds Company (Figure 3), and the measurement temperature was $20 \pm 1^{\circ} \mathrm{C}$. When measuring, a single pitch diameter probe is used to measure the pitch diameter value for every $30^{\circ}$, and the first 3 complete threads are measured for each threaded hole. After the measurement is completed, the maximum and minimum pitch diameter of each complete thread in the radial position is found, and then (1) is used to determine the RPDD of each thread. The values of RPDD are calculated as the average of three measurements taken from these three threads.

2.2. Preparation of the Cutting Edge. At present, there are many preparation methods for hone radius, such as grinding, abrasive jet processing, laser processing, and electrochemical machining, but only electrochemical machining is suitable for the preparation of complex tools, so it is the best choice for the preparation of tap hone radius. Electrochemical machining is the result of the combined effect of the anode film effect and tip effect [17]. As shown in Figure 4, a high-resistance anode film of varying thickness is wrapped around the tool. Due to the tip effect, the film near the cutting edge is thin, the current is large, which causes a large amount of cutting edge material to be quickly dissolved, and the cutting edge gradually becomes rounded. Figure 4 shows the electrochemical machining equipment. In electrochemical machining, the tap is connected to the anode of the power source, and the graphite plate is selected as the cathode. Experimental conditions: the electrolysis power supply is a $24 \mathrm{~V}$ DC power supply, the electrolysis current is $3 \mathrm{~A}$, the spindle speed is $120 \mathrm{rev} / \mathrm{min}$, the electrolyte is the electrolytic polishing fluid produced by Foshan Adekron Electromechanical Technology Co., Ltd., and the electrolyte temperature is $25^{\circ} \mathrm{C}$. In the experiment, the hone radii of different sizes were prepared by changing the electrolytic electric quantity. The specific parameters are shown in Table 3.

2.3. Taguchi Method. Taguchi method proposes a unique orthogonal array design to improve the quality of products and effectively reduce the number of experiments. It is an efficient, fast, and economical experimental design method. In this study, the influence of the three factors of hone radius, spindle speed, and chamfer length on RPDD is mainly considered. According to the actual situation, different levels are selected for the three factors, and the specific values are shown in Table 4 . Since the level of each factor in the experiment is different and the interaction between the 


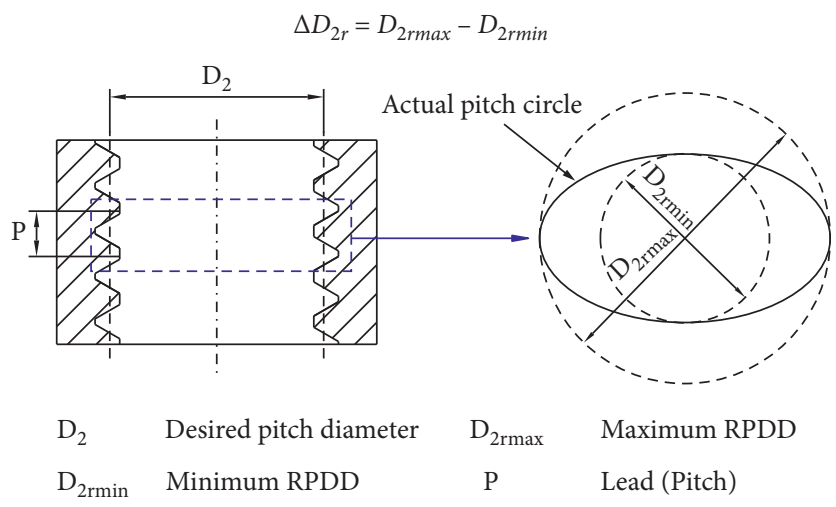

FIgURE 1: Schematic diagram of RPDD.

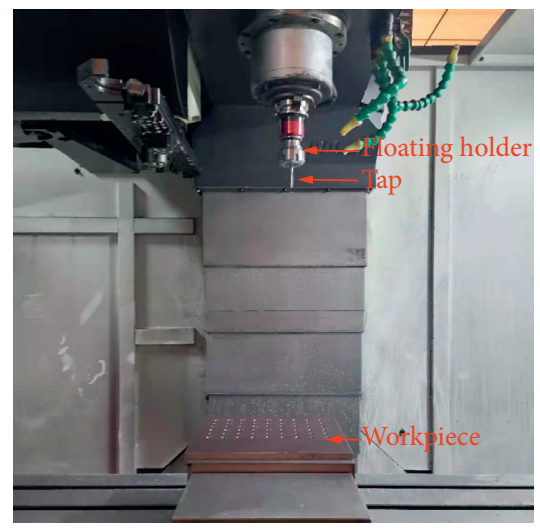

(a)

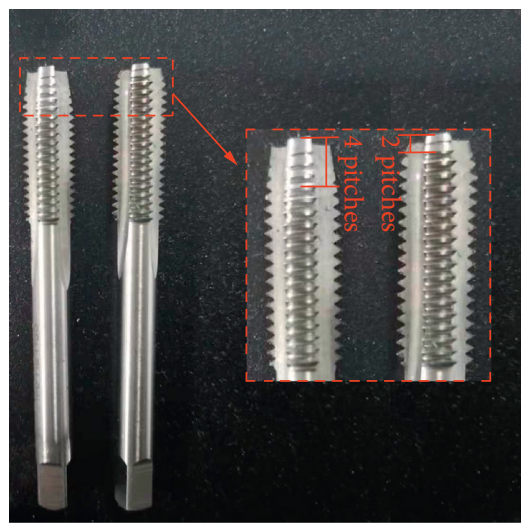

(b)

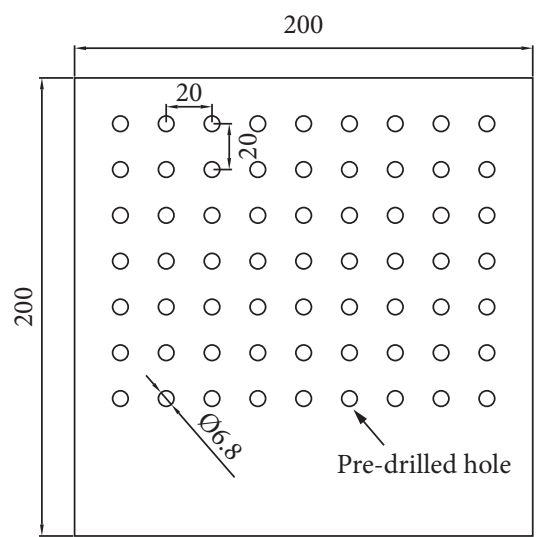

(c)

FIGURE 2: Machine tool and materials. (a) VMC850 vertical machining center. (b) Straight flute taps with different chamfer lengths. (c) Sample specification.

Table 1: Geometric parameters of taps.

\begin{tabular}{lc}
\hline Parameter & Value \\
\hline Nominal diameter $(\mathrm{mm})$ & 8 \\
Tap length $(\mathrm{mm})$ & 72 \\
Pitch $(\mathrm{mm})$ & 1.25 \\
Rake angle $(\mathrm{deg})$ & 7 \\
Flank angle $(\mathrm{deg})$ & 5 \\
Flute number & 3 \\
Hone radius $(\mu \mathrm{m})$ & $0,10,20$ \\
Chamfer length $(\mu \mathrm{m})$ & 2,4 \\
\hline
\end{tabular}

Table 2: Chemical composition of AISI H13.

\begin{tabular}{lr}
\hline Composition & $\begin{array}{c}\text { Weight percent } \\
(\%)\end{array}$ \\
\hline $\mathrm{C}$ & $0.32 \sim 0.45$ \\
$\mathrm{Si}$ & $0.80 \sim 1.20$ \\
$\mathrm{Mn}$ & $0.20 \sim 0.50$ \\
$\mathrm{Cr}$ & $4.75 \sim 5.50$ \\
$\mathrm{Mo}$ & $1.10 \sim 1.75$ \\
$\mathrm{~V}$ & $0.80 \sim 1.20$ \\
$\mathrm{P}$ & $\leq 0.03$ \\
$\mathrm{~S}$ & $\leq 0.03$ \\
\hline
\end{tabular}



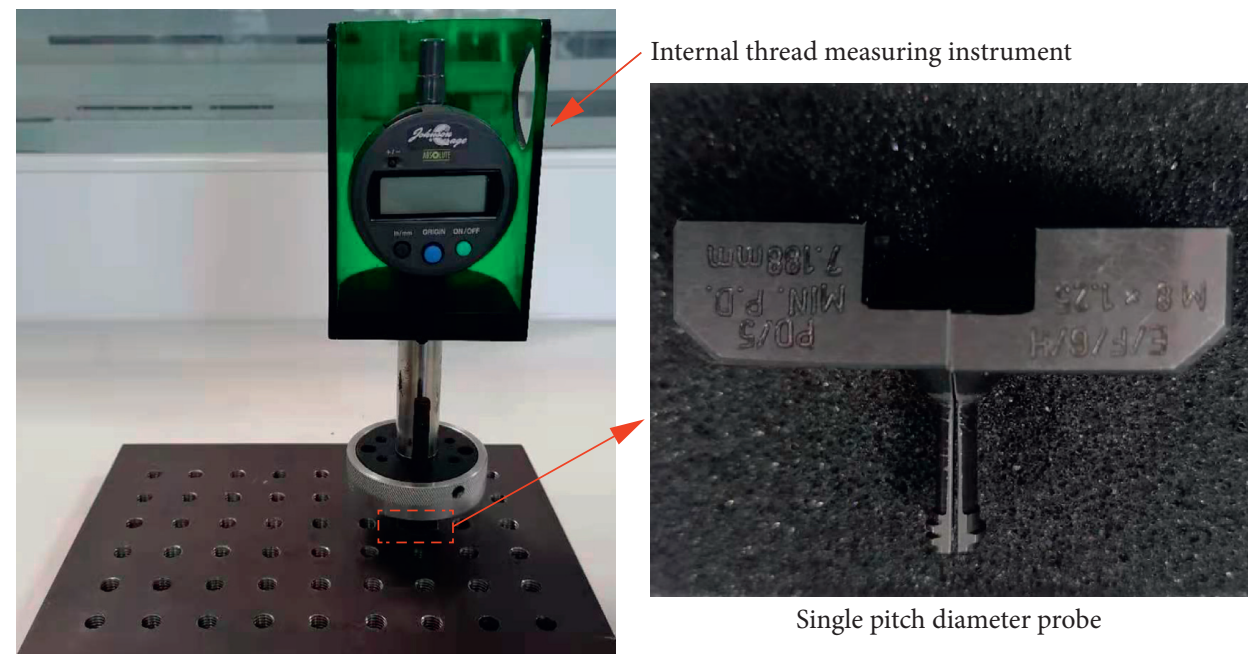

Single pitch diameter probe

Figure 3: GJ-5S internal thread measuring instrument.

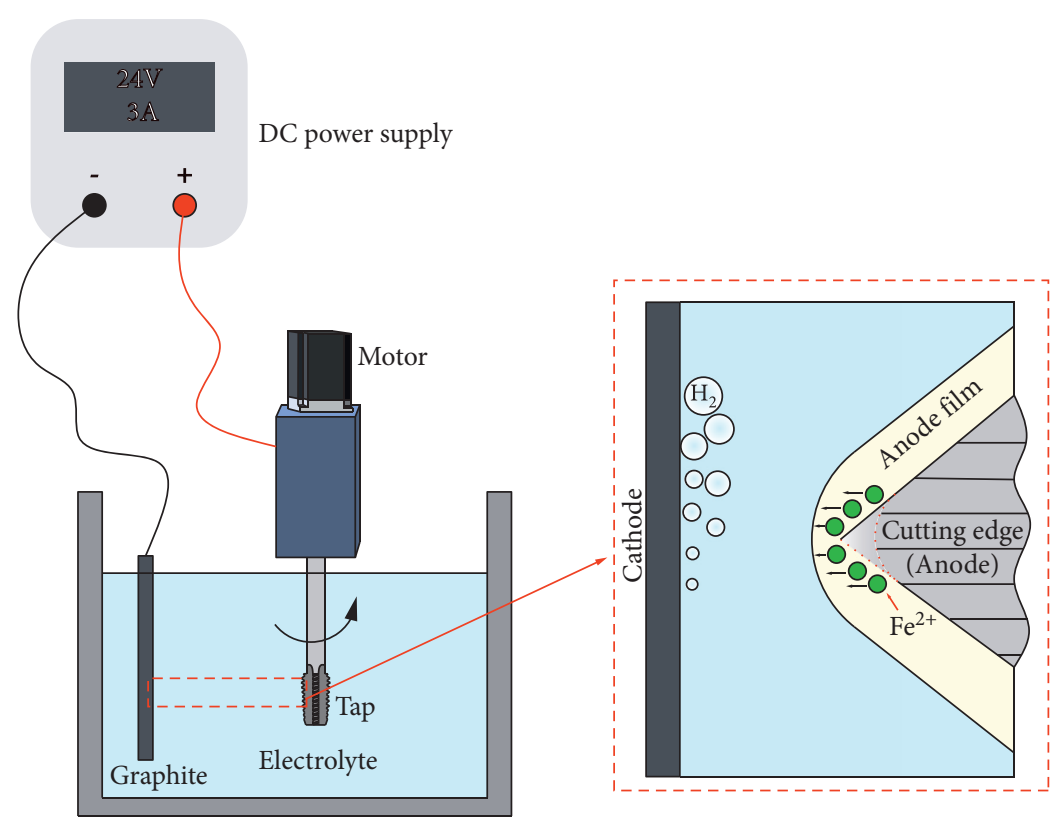

(a)

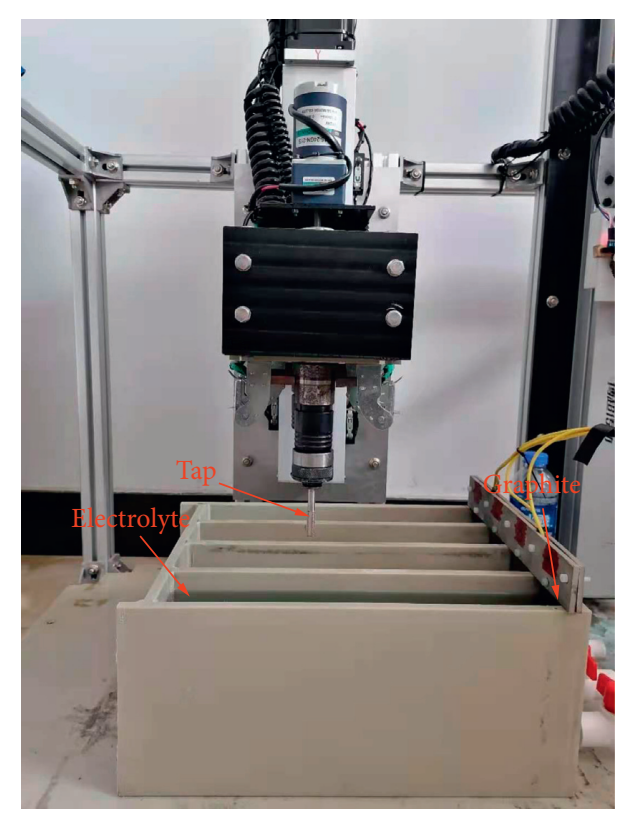

(b)

FIGURE 4: Electrolysis principle and equipment.

Table 3: Preparation parameters of hone radius.

\begin{tabular}{lcc}
\hline $\begin{array}{l}\text { Hone radius } \\
(\mu \mathrm{m})\end{array}$ & $\begin{array}{c}\text { Electric quantity } \\
(\mathrm{C})\end{array}$ & Time $(\mathrm{s})$ \\
\hline 10 & 53 & 12 \\
20 & 100 & 29 \\
\hline
\end{tabular}

TABLE 4: Factors and levels.

\begin{tabular}{lccc}
\hline Level & $\begin{array}{c}\text { Chamfer length (A) } \\
\text { (pitches) }\end{array}$ & $\begin{array}{c}\text { Spindle speed }(\mathrm{B}) \\
(\mathrm{rev} / \mathrm{min})\end{array}$ & $\begin{array}{c}\text { Hone radius }(\mathrm{C}) \\
(\mu \mathrm{m})\end{array}$ \\
\hline 1 & 2 & 100 & 0 \\
2 & 4 & 300 & 10 \\
3 & & 500 & 20 \\
\hline
\end{tabular}


factors is not considered, the L18 $\left(2^{1} \times 3^{2}\right)$ mixed-level orthogonal table is selected to arrange the experiment.

\section{Results and Discussion}

3.1. Signal-to-Noise Ratio. Taguchi method uses a signal-tonoise ratio to measure quality characteristics that deviate from the desired value. There are generally three types of quality characteristics; the-lower-the-better, the-nominalthe-best, and the-higher-the-better. The purpose of this study is to obtain the smallest RPDD, so the lower-the-better $\mathrm{S} / \mathrm{N}$ is adopted. The equation of $\mathrm{S} / \mathrm{N}$ can be expressed as [18]

$$
\eta=\left(\frac{S}{N}\right)=-10 \log \left(\frac{1}{n} \sum_{i=1}^{n} y_{i}^{2}\right),
$$

where $\eta$ is the lower-the-better $\mathrm{S} / \mathrm{N}$ (unit: $\mathrm{dB}$ ), $y_{i}$ represents RPDD based on the experimental results, and $n$ represents the number of repetitions in the experiment. The experiment results of RPDD and the corresponding S/N obtained from equation (2) are shown in Table 5 . The $\mathrm{S} / \mathrm{N}$ of each factor is obtained by calculating the arithmetic mean value of its corresponding levels, where the level with the highest $\mathrm{S} / \mathrm{N}$ is the optimal level of the factor. Table 6 shows the S/N response of each factor to RPDD. It can be seen from the table that the combination of factors to obtain the optimum RPDD during AISI H13 tapping are A1, B1, and C2. Figure 5 is the main effect diagram of the $\mathrm{S} / \mathrm{N}$ of Table 6 which shows the $\mathrm{S} / \mathrm{N}$ response of each factor to RPDD. Same as the S/N response table, the peak point of $S / N$ in the main effect diagram shows the optimal level of this factor. Therefore, the optimal values of Table 6 show the S/N response of each factor to RPDD determined according to the chamfer length, spindle speed, and hone radius are 2 pitches, $100 \mathrm{rev} / \mathrm{min}$, and $10 \mu \mathrm{m}$, respectively.

3.2. Variance Analysis. The purpose of the analysis of variance is to determine the influence of design parameters on quality characteristics [19]. The factor that has the greatest influence on RPDD among the parameters of ANOVA is determined. Table 7 lists the percent contribution ratio (PCR) of the influence level of each parameter on the experiment results of RPDD and analyzes the obtained results. According to Table 7, it is found that the spindle speed (PCR: $61.54 \%$ ) is the main factor affecting RPDD, followed by the hone radius (PCR: $24.53 \%$ ) and the chamfer length (PCR: $6.16 \%$ ). Therefore, the most effective factor for RPDD is the spindle speed. In addition, the $\mathrm{S} / \mathrm{N}$ response results in $\mathrm{Ta}-$ ble 6 and the results of the main effect plot in Figure 5 were verified by ANOVA.

3.3. Regression Analysis. Regression analysis is an analysis method that combines statistical and mathematical techniques. It is generally used to explain the quantitative relationship between response and independent factors. In this study, the factors are chamfer length, spindle speed, and hone radius, whereas the response is RPDD. The empirical data were used to construct a quadratic polynomial model by RA. The quadratic polynomial model is expressed as [20]

$$
y=\beta_{0}+\sum_{i=1}^{k} \beta_{i} x_{i}+\sum_{i=1}^{k} \beta_{i i} x_{i}^{2}+\sum_{i, j=1, i \neq j}^{k} \beta_{i j} x_{i} x_{j},
$$

where $\beta_{0}$ is the free term coefficient in the regression equation and $\beta_{1}, \beta_{2}, \ldots, \beta_{k}$ and $\beta_{11}, \beta_{22}, \ldots \beta_{k k}$ are the linear and the quadratic term coefficients, respectively, while $\beta_{12}$, $\beta_{13}, \ldots, \beta_{k 1}$ are the interacting term coefficients. $y$ is the response, $x_{\mathrm{i}}$ is the factors, and $k$ is the number of factors. According to the above quadratic polynomial model, the prediction equation for RPDD obtained by RA is as follows:

$$
\begin{aligned}
\mathrm{RPDD}= & 8.39+0.597 A+0.06763 B-0.544 C-0.000105 B^{2} \\
& +0.02325 C^{2}+0.0058 A C-0.000087 B C .
\end{aligned}
$$

The determination coefficient $R^{2}$ of the prediction equation is 0.925 . The determination coefficient $R^{2}$ of the prediction equation is close to 1 , which shows that the predicted value is in good agreement with the experimental value. Figure 6(a) is the normal probability plot of the residuals of RPDD. It can be seen from the figure that the residuals are approximately arranged on a straight line. This means that the error is normally distributed, and the terms mentioned in the model are significant [21]. As shown in Figure 6(b), the maximum residual of RPDD of 1.55 is within an acceptable range, which means the importance of the established equation. Figure 7 shows that the predicted value of RPDD is very close to the experimental value, which shows that the correlation between them is very good [22]. Therefore, the equation proved to be an effective method for predicting RPDD.

Figure 8 is a 3D mapping surface of RPDD obtained from the prediction equation. The figure shows the influence of spindle speed and hone radius on RPDD. From the comparison of Figures $8(a)$ and $8(b)$, it can be found that the RPDD obtained by a tool with a chamfer length of 2 pitches is generally smaller than that of a tool with a chamfer length of 4 pitches, and both figures show that the RPDD obtained at the lowest spindle speed and a medium hone radius is the smallest. Therefore, in order to obtain the smallest RPDD, AISI H13 tapping needs to be carried out by using a tool with a chamfer length of 2 pitches at the lowest spindle speed and medium hone radius.

3.4. Confirmation Experiments. The confirmation experiment is the last step of the optimization process, and the purpose is to evaluate whether the optimization conditions are effective. In this study, the Taguchi method and prediction equations were validated. When performing confirmation experiment on the Taguchi method, the optimum RPDD ( $\left(\mathrm{RPDD}_{\text {opt }}\right)$ is obtained by

$$
\begin{aligned}
\mathrm{RPDD}_{\mathrm{opt}} & =10^{-\eta_{G} / 20}, \\
\eta_{G} & =\eta_{m}+\sum_{i=1}^{k}\left(\eta_{i}-\eta_{m}\right),
\end{aligned}
$$


TABLe 5: Experimental results and S/N.

\begin{tabular}{|c|c|c|c|c|c|}
\hline Exp. no. & $\mathrm{A}$ & $\mathrm{B}$ & $\mathrm{C}$ & $\operatorname{RPDD}(\mu \mathrm{m})$ & $\begin{array}{l}\mathrm{S} / \mathrm{N} \\
(\mathrm{dB})\end{array}$ \\
\hline 1 & 1 & 1 & 1 & 15.7 & -23.9 \\
\hline 2 & 1 & 1 & 2 & 12.4 & -21.9 \\
\hline 3 & 1 & 1 & 3 & 14.6 & -23.3 \\
\hline 4 & 1 & 2 & 1 & 19.8 & -25.9 \\
\hline 5 & 1 & 2 & 2 & 16.5 & -24.3 \\
\hline 6 & 1 & 2 & 3 & 17 & -24.6 \\
\hline 7 & 1 & 3 & 1 & 17.3 & -24.8 \\
\hline 8 & 1 & 3 & 2 & 14.3 & -23.1 \\
\hline 9 & 1 & 3 & 3 & 15.6 & -23.9 \\
\hline 10 & 2 & 1 & 1 & 15.9 & -24.0 \\
\hline 11 & 2 & 1 & 2 & 12.9 & -22.2 \\
\hline 12 & 2 & 1 & 3 & 15 & -23.5 \\
\hline 13 & 2 & 2 & 1 & 23 & -27.2 \\
\hline 14 & 2 & 2 & 2 & 19.2 & -25.7 \\
\hline 15 & 2 & 2 & 3 & 20.7 & -26.3 \\
\hline 16 & 2 & 3 & 1 & 17.6 & -24.9 \\
\hline 17 & 2 & 3 & 2 & 14.8 & -23.4 \\
\hline 18 & 2 & 3 & 3 & 15.9 & -24.0 \\
\hline
\end{tabular}

TABle 6: S/N response.

\begin{tabular}{lccc}
\hline Level & \multicolumn{3}{c}{ Mean S/N ratio } \\
\hline 1 & A & B & -25.13 \\
2 & -23.97 & -23.14 & -23.43 \\
3 & -24.59 & -25.69 & -24.27 \\
Max-min & & -24.01 & 1.70 \\
\hline
\end{tabular}

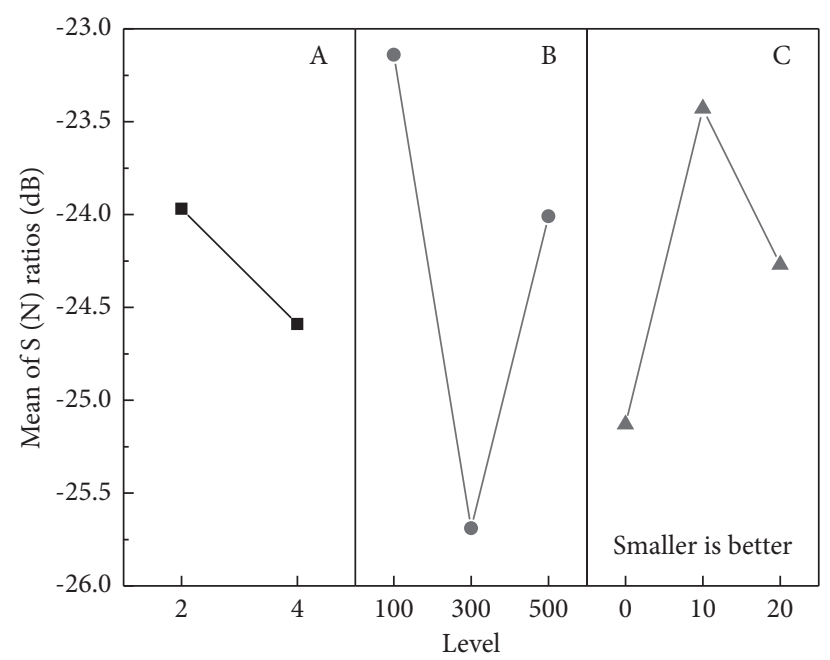

FIgURe 5: Main effect diagram of S/N for RPDD.

TABLE 7: ANOVA for RPDD.

\begin{tabular}{lccccr}
\hline & DoF & SS & MS & $F$ test & $\begin{array}{c}\text { PCR value } \\
(\%)\end{array}$ \\
\hline A & 1 & 7.74 & 7.74 & 9.51 & 0.009 \\
B & 2 & 77.31 & 38.66 & 47.51 & $\leq 0.001$ \\
C & 2 & 30.81 & 15.41 & 18.93 & $\leq 0.001$ \\
Re & 12 & 9.76 & 0.81 & & 24.53 \\
Total & 17 & 125.62 & & & 7.77 \\
\hline
\end{tabular}

DoF: degrees of freedom; SS: sequential sum of squares; MS: mean sum of squares; Re: residual error. 


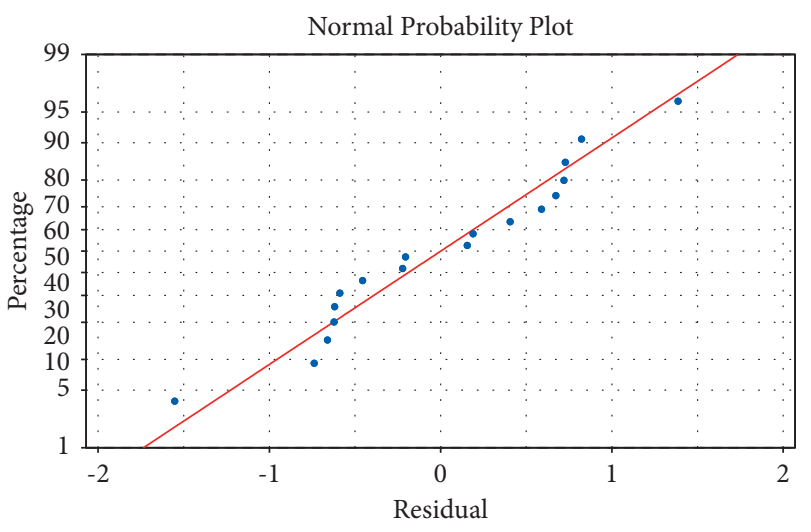

(a)

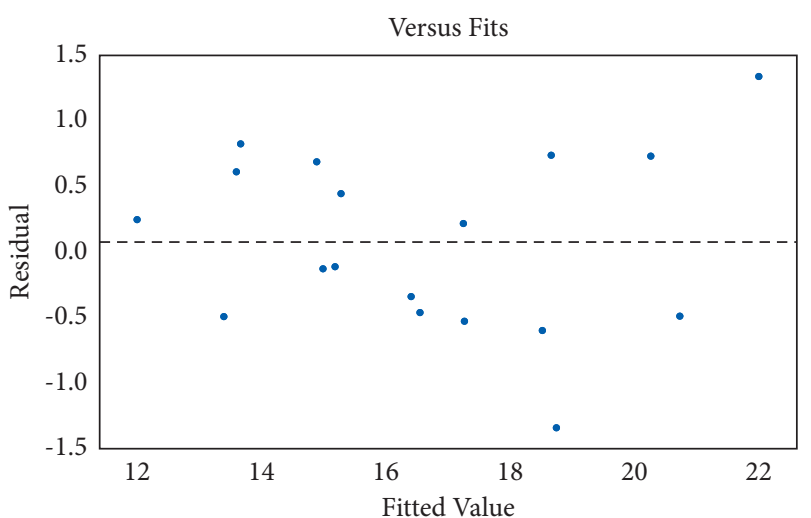

(b)

Figure 6: Statistical results for RPDD. (a) Normal probability plot (b) versus fits.

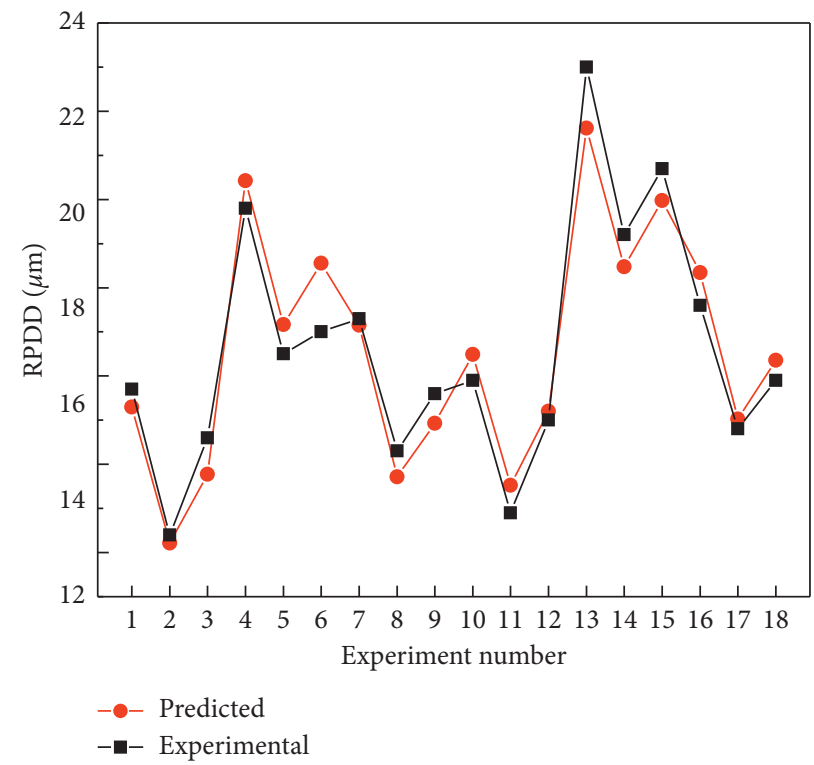

Figure 7: Comparison between experimental and predicted values.

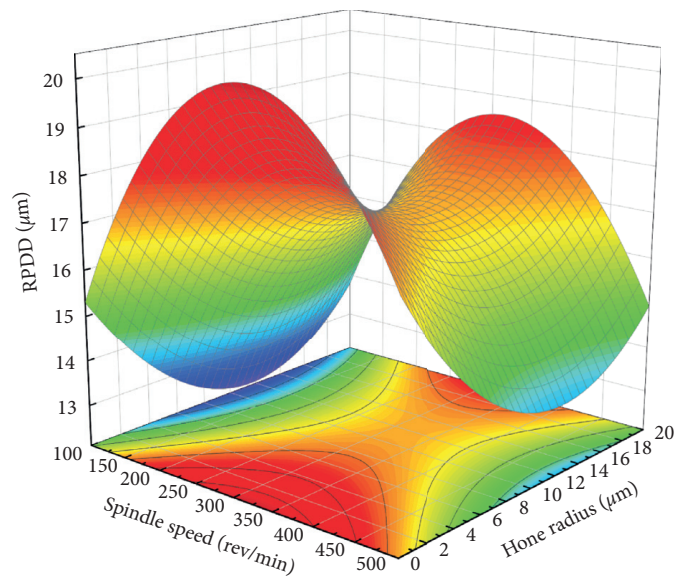

(a)

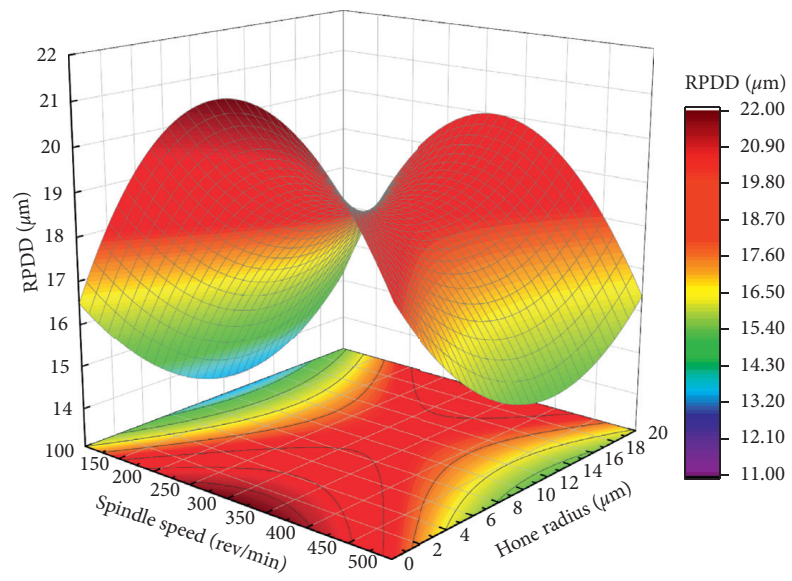

(b)

Figure 8: 3D mapping surfaces of RPDD. (a) 2 pitches. (b) 4 pitches. 
TABLE 8: Predicted values and confirmation experiment results by Taguchi method and regression equations.

\begin{tabular}{|c|c|c|c|c|c|}
\hline \multirow[t]{2}{*}{ Level } & \multirow[t]{2}{*}{ Exp. } & \multicolumn{2}{|c|}{ Taguchi method } & \multicolumn{2}{|c|}{$\begin{array}{c}\text { Prediction } \\
\text { equation }\end{array}$} \\
\hline & & Pre. & Error (\%) & Pre. & Error (\%) \\
\hline A1B1C2 (OPT.) & 12.4 & 12.56 & 1.27 & 12.21 & 1.56 \\
\hline A2B1C3 (RAN.) & 15 & 14.86 & 0.94 & 15.20 & 1.32 \\
\hline A1B2C2 (RAN.) & 16.5 & 16.85 & 2.08 & 17.16 & 3.85 \\
\hline
\end{tabular}

where $\eta_{G}$ is the $\mathrm{S} / \mathrm{N}$ calculated at the optimal level, $\eta_{m}$ is the average $\mathrm{S} / \mathrm{N}$ of all experiments in Table $5, \eta_{i}$ is the average $\mathrm{S} / \mathrm{N}$ at the optimal level of each factor, and $k$ is the number of factors that affect RPDD [23].

In the confirmation experiment, the confirmation experiment value should fall within the confidence interval (CI). If the reliability of the assumption is $95 \%$, the confidence interval can be calculated by the following equation [24]:

$$
\begin{aligned}
\mathrm{CI} & =\sqrt{F_{\alpha, 1, \mathrm{DoFe}} \times \mathrm{MS}_{e}\left(\frac{1}{n_{\mathrm{eff}}}+\frac{1}{R}\right)}, \\
n_{\mathrm{eff}} & =\frac{N}{1+T_{\mathrm{DoF}}},
\end{aligned}
$$

where $F_{\alpha, 1, \mathrm{DoFe}}$ is the $F$ ratio under the $\alpha$ confidence level, $\mathrm{DoFe}$ is the error degree of freedom, $\mathrm{MS}_{\mathrm{e}}$ is the error variance, $n_{\mathrm{eff}}$ is the effective number of repetitions of the experiment, $R$ is the number of repetitions of the confirmation experiment, $N$ is the total number of experiments, and $T_{\mathrm{DoF}}$ is the total degree of freedom of the main factor.

In this study, $F_{95 \%, 1,12}=4.747, \mathrm{MS}_{\mathrm{e}}=0.81, R=3, N=18$, $T_{\mathrm{DoF}}=5$, and $n_{\mathrm{eff}}=3$. By using equations (7) and (8) to calculate, $\mathrm{CI}=1.60$, which means that the result of the confirmation experiment should fall within the following range:

$\mathrm{RPDD}_{\text {opt }}-\mathrm{CI}<\mathrm{RPDD}_{\text {exp }}<\mathrm{RPDD}_{\text {opt }}+\mathrm{CI}=10.96<12.4<14.17$.

Taguchi method and prediction equation are confirmed at the optimal and random levels. In Table 8, the experimental results are compared with the predicted values obtained by the Taguchi method and prediction equation. The error value between the predicted value and the experimental value is less than $20 \%$, and the statistical analysis is reliable [25]. Therefore, the results obtained from the confirmation experiment indicate a successful optimization.

\section{Conclusions}

Tapping is the only method for manufacturing small-diameter internal threads. Due to the harsh processing conditions, the processing quality is difficult to guarantee. RPDD is a very important parameter to evaluate the quality of thread manufacturing, but there are few literatures on RPDD in tapping. Therefore, in order to ensure the quality of thread manufacturing, in this paper, the parameters that affect RPDD when tapping AISI H13 are optimized based on Taguchi experimental design, and RPDD is modeled based on regression analysis. The specific research conclusions are as follows:

(i) Through the analysis of $\mathrm{S} / \mathrm{N}$, the combination of optimum parameters for the minimum RPDD has been obtained: the chamfer length of 2 pitches, spindle speed of $100 \mathrm{rev} / \mathrm{min}$, and hone radius of $10 \mu \mathrm{m}$.

(ii) According to the results of ANOVA, the PCR of factors A, B, and C on RPDD are 6.16\%, 61.54\%, and $24.53 \%$, respectively, among which spindle speed (factor B, 61.54\%) is the most important factor affecting RPDD.

(iii) The RPDD prediction equation is established by RA. The determination coefficient $R^{2}$ of the prediction equation is 0.925 , and the prediction results of the equation are in good agreement with the experimental results.

(iv) The 95\% confidence level confirmation experiment shows that the Taguchi method and prediction equation have successfully realized the optimization and prediction of RPDD.

\section{Data Availability}

Data sharing is not applicable.

\section{Conflicts of Interest}

The authors declare that there are no conflicts of interest regarding the publication of this paper.

\section{Authors' Contributions}

Jie Ren and Tingting Li contributed equally to this work.

\section{Acknowledgments}

This research was funded by the National Natural Science Foundation of China, (no. 51275333).

\section{References}

[1] Y. Dong and D. P. Hess, "The effect of thread dimensional conformance on vibration-induced loosening," Journal of Vibration and Acoustics, vol. 121, no. 2, pp. 209-213, 1999.

[2] E. Fetullazade, H. K. Akyildiz, and S. Saritas, "Effects of the machining conditions on the strain hardening and the residual stresses at the roots of screw threads," Materials \& Design, vol. 31, no. 4, pp. 2025-2031, 2010.

[3] I. Korin and J. Perez Ipiña, "Experimental evaluation of fatigue life and fatigue crack growth in a tension bolt-nut threaded connection," International Journal of Fatigue, vol. 33, no. 2, pp. 166-175, 2011.

[4] P. Monka, K. Monkova, V. Modrak, S. Hric, and P. Pastucha, "Study of a tap failure at the internal threads machining," Engineering Failure Analysis, vol. 100, pp. 25-36, 2019.

[5] O. Onysko, V. Panchuk, V. Kopei, Y. Havryliv, and I. Schuliar, "Investigation of the influence of the cutter-tool rake angle on 
the accuracy of the conical helix in the tapered thread machining," Journal of Physics: Conference Series, vol. 1781, no. 1, 9 pages, Article ID 012028, 2021.

[6] J. Min, "Comprehensive measurement system for screw thread parameter based on machine vision," in Proceedings of the 2015 International Conference on Computer and Computational Sciences (ICCCS), pp. 266-270, Greater Noida, India, January 2015.

[7] B. dos Santos Siqueira, S. A. Freitas, R. B. D. Pereira, C. H. Lauro, and C. BrandãoL, "Influence of chip breaker and helix angle on cutting efforts in the internal threading process," International Journal of Advanced Manufacturing Technology, vol. 102, no. 5, pp. 1537-1546, 2019.

[8] M. Wan and Y. Altintas, "Mechanics and dynamics of thread milling process," International Journal of Machine Tools and Manufacture, vol. 87, pp. 16-26, 2014.

[9] A. O. De Carvalho, L. C. Brandão, T. H. Panzera, and C. H. Lauro, "Analysis of form threads using fluteless taps in cast magnesium alloy (AM60)," Journal of Materials Processing Technology, vol. 212, no. 8, pp. 1753-1760, 2012.

[10] I. C. Pereira, M. B. Da Silva, D. F. Da Cunha, and W. F. Sales, "Analysis of tapping process in three types of cast iron," International Journal of Advanced Manufacturing Technology, vol. 82, no. 5, pp. 1041-1048, 2016.

[11] C. C. Hsu, S. S. Yeh, and J. I. Lee, "Effect analysis and optimal combination of cutting conditions on the cutting torque of tapping processes using Taguchi methods," in Proceedings of the 2016 IEEE International Conference on Automation Science and Engineering (CASE), pp. 1215-1218, Fort Worth, TX, August 2016.

[12] J. Fernández Landeta, A. Fernández Valdivielso, L. N. López de Lacalle, F. Girot, and M. Pérez PérezJ, "Wear of form taps in threading of steel cold forged parts," Journal of Manufacturing Science and Engineering, vol. 137, p. 11, Article ID 031002, 2015.

[13] A. P. S. Dogra, S. G. Kapoor, and R. E. DeVor, "Mechanistic model for tapping process with emphasis on process faults and hole geometry," Journal of Manufacturing Science and Engineering, vol. 124, no. 1, pp. 18-25, 2001.

[14] V. K. Vankanti and V. Ganta, "Optimization of process parameters in drilling of GFRP composite using Taguchi method," Journal of Materials Research and Technology, vol. 3, no. 1, pp. 35-41, 2014.

[15] S. Ahmed and R. Arora, "Optimization of turning parameters of Aluminum 6351 T6 using Taguchi decision making technique," International Journal of Data and Network Science, vol. 1, no. 2, pp. 27-38, 2017.

[16] S. Bhattacharyya, H. Chelladurai, and M. Z. Ansari, "Effect of micro-milling parameters on surface roughness of soft metal cutting and their regression models," in Proceedings of the Recent Advances in Manufacturing, Automation, Design and Energy Technologies, pp. 221-228, Karaikal, Puducherry, India, October 2022.

[17] M. Schneider and M. Lohrengel, "Electrochemical machining," in Springer Handbook of Electrochemical Energy, C. Breitkopf and K. Swider-Lyons, Eds., pp. 941-971, Springer, Berlin, Heidelberg, 2017.

[18] C. J. Slebi-Acevedo, P. Pascual-Muñoz, P. Lastra-González, and D. Castro-Fresno, "Multi-response optimization of porous asphalt mixtures reinforced with aramid and polyolefin fibers employing the CRITIC-TOPSIS based on Taguchi methodology," Materials, vol. 12, no. 22, 24 pages, Article ID 3789, 2019.
[19] R. Çakıroğlu and A. Acır, "Optimization of cutting parameters on drill bit temperature in drilling by Taguchi method," Measurement, vol. 46, no. 9, pp. 3525-3531, 2013.

[20] R. S. Anand and K. Patra, "Cutting force and hole quality analysis in micro-drilling of CFRP," Materials and Manufacturing Processes, vol. 33, no. 12, pp. 1369-1377, 2018.

[21] A. K. Sahoo and B. Sahoo, "A comparative study on performance of multilayer coated and uncoated carbide inserts when turning AISI D2 steel under dry environment," Measurement, vol. 46, no. 8, pp. 2695-2704, 2013.

[22] C. Leone, D. D’Addona, and R. Teti, “Tool wear modelling through regression analysis and intelligent methods for nickel base alloy machining," CIRP Journal of Manufacturing Science and Technology, vol. 4, no. 3, pp. 327-331, 2011.

[23] G. Basar, F. Kahraman, F. Kahraman, and Y. Fedai, "Modeling and optimization of face milling process parameters for AISI 4140 steel," Tehnički glasnik, vol. 12, no. 1, pp. 5-10, 2018.

[24] F. Kara and B. Öztürk, "Comparison and optimization of PVD and CVD method on surface roughness and flank wear in hard-machining of DIN 1.2738 mold steel," Sensor Review, vol. 39, no. 1, pp. 24-33, 2018.

[25] T. Kivak, "Optimization of surface roughness and flank wear using the Taguchi method in milling of Hadfield steel with PVD and CVD coated inserts," Measurement, vol. 50, pp. 19-28, 2014. 